\title{
IDENTIFIKASI KEPUASAN KONSUMEN TERHADAP ATRIBUT PRODUK PEMBANGKIT LISTRIK ENERGI ALTERNATIF DENGAN MENGGUNAKAN KANO'S MODEL DI LANGKAT
}

\author{
ROSNANI GINTING ${ }^{1}$, IKHSAN SIREGAR ${ }^{2}$ \\ Dosen Departemen Teknik Industri ${ }^{1,2}$ \\ Fakultas Teknik, Universitas Sumatera Utara \\ Medan 20155 \\ Email : rosnani_usu@yahoo.co.id \\ Email : siregar_ix@yahoo.com
}

\begin{abstract}
Abstrak. Alternative energy is a term that refers to all usable energy that aims to replace conventional fuels without any unintended consequences. In the context of this research, alternative energy is meant as renewable energy. Renewable energy is energy generated from natural sources, such as sunlight, wind, rain, tidal currents, and geothermal, which are renewable or can reappear naturally after its utilization. Many methods, procedures and techniques are adopted by the customer satisfaction as enhanced by the design of An Alternative Energy Utilization. This study seeks an assessment of user satisfaction, which in this case is the community, to combine Quality Function Deployment and Kano's model as design techniques in product design and development by focusing on capturing and translating consumer desires into a product design. The calculation results show the most important characteristic to be immediately corrected is Technology sophistication and Production Cost with the highest cost estimate, the degree of importanceand difficulty level. From the planning matrix obtained the product attribute that is Generation Price and Durability become the priority of improvement because it has the biggest weight.
\end{abstract}

Keyword. Alternative energy, QFD, Kano's Model 


\section{Pendahuluan}

Permintaan energi dunia terus meningkat sepanjang sejarah peradaban umat manusia. Proyeksi permintaan energi pada tahun 2050 hampir mencapai tiga kali lipat. Tampaknya masalah energi akan tetap menjadi topik yang harus dicarikan solusinya secara bersama-sama. Pemanfaatan energi telah berkembang dan meningkat sesuai dengan perkembangan manusia itu sendiri. Usaha-usaha untuk mendapatkan energi alternatif telah lama dilakukan untuk mengurangi ketergantungan terhadap sumber daya minyak bumi. Pemanfaatan minyak bumi diperkirakan akan habis dalam waktu yang tidak lama jika pola pemakaian seperti sekarang ini yang justru semakin meningkat dengan meningkatnya industri maupun transportasi. Selain itu dari berbagai penelitian telah didapat gambaran bahwa kualitas udara telah semakin mengkawatirkan akibat pembakaran minyak bumi (Widodo, Suryono, Tatyantoro, Tugino. 2009).

Energi merupakan salah satu kebutuhan utama dalam kehidupan manusia. Peningkatan kebutuhan energi dapat merupakan indikator peningkatan kemakmuran, namun bersamaan dengan itu juga menimbulkan masalah dalam usaha penyediaannya, karena manusia hanya mengandalkan energi fosil yang tentunya persediannya masih sangat terbatas dan semakin menipis. Karena tergolong unrenewable, maka akibat dikuras terus - menerus, persediaan energi tersebut semakin berkurang dan tidak bisa diupayakan kembali keberadaanya. Sehingga bukan suatu hal yang mustahil jika dimasa-masa yang akan datang akan timbul masalah-masalah yang berkaitan dengan krisis energi. Untuk mengantisipasi persediaan energi di masa yang akan datang, sejak dua dekade terakhir ratusan pakar energi dari berbagai Negara saling berlomba untuk mengupayakan penemuan-penemuan baru tentang sumber energi alternatif yang tidak saja efisien tetapi juga bernuansa ramah lingkungan. Dan salah satu pilihannya adalah sel surya, walaupun secara efisiensi masih perlu pertimbangan lebih jauh (Sidopekso dan Febtiwiyanti, 2010).

Sementara itu, potensi air sebagai sumber energi terutama digunakan sebagai penyedia energi listrik melalui pembangkit listrik tenaga air maupun mikrohidro. Pemanfaatan energi air pada dasarnya adalah pemanfaatan energi potensial gravitasi. Energi mekanik aliran air yang merupakan transformasi dari energi potensial gravitasi dimanfaatkan untuk menggerakkan turbin atau kincir. Dalam menggerakkan kincir, aliran air pada sungai dapat dimanfaatkan ketika kecepatan alirannya memadai (Purnama, Hantoro, Nugroho, 2013). Untuk pemanfaatan tenaga angin, Potensi energi angin di Indonesia umumnya berkecepatan lebih dari 5 meter per detik (m/detik). Hasil pemetaan Lembaga Penerbangan dan Antariksa Nasional (Lapan) pada 120 lokasi menunjukkan, beberapa wilayah memiliki kecepatan angin di atas
5 m/detik, masing-masing Nusa Tenggara Timur, Nusa Tenggara Barat, Sulawesi Selatan, dan Pantai Selatan Jawa. Adapun kecepatan angin $4 \mathrm{~m} /$ detik hingga $5 \mathrm{~m} /$ detik tergolong berskala menengah dengan potensi kapasitas 10-100 kW. (Kompas GSA. 2012).

Kabupaten Langkat adalah sebuah kabupaten yang terletak di Sumatera Utara, Indonesia. Ibu kotanya berada di Stabat. Kabupaten Langkat secara administratif terdiri dari 20 kecamatan dengan 215 desa dan 15 kelurahan. Luas wilayah Kabupaten Daerah Langkat adalah 6.263,29 Km2 atau 626.329 Ha, dengan jumlah penduduk 926.069 jiwa. Secara geografis letak Kabupaten Langkat berada antara 3014'00" dan 4013'00" Lintang Utara dan antara 97052'00" dan 98045'00" Bujur Timur. Luas wilayah Kabupaten Langkat $6.263,29 \mathrm{~km} 2$ atau 8,74 persen dari total luas Provinsi Sumatera Utara. Kabupaten Langkat berada pada ketinggian 4-105 m di atas permukaan laut sehingga sebagiann besar wilayahnya merupakan daratan rendah. Kabupaten Langkat beriklim tropis dan mempunyai dua musim yaitu musim kemarau dan musim hujan. Musim hujan pertama mulai bulan Agustus sampai dengan bulan Januari dan musim kedua pada bulan Maret sampai dengan bulan Mei, sedangkan musim kemarau biasanya pada bulan Februari, Juni dan Juli (Badan Pusat Statistik Kabupaten Langkat, 2013).

Kabupaten Langkat mengalami curah hujan sebanyak 3.289,94 mm dengan lama hujan 150,83 hari pada tahun 2012 dengan rata-rata total curah hujan tertinggi terjadi pada bulan November sebesar 408,88 mm dengan hari hujan sebanyak 18 hari kemudian pada bulan September sebesar 376,88 mm dengan hari hujan sebanyak 15 hari (Badan Pusat Statistik Kabupaten Langkat, 2013). Secara topografi, Langkat dibedakan atas tiga bagian, yaitu Pesisir Pantai dengan ketinggian $0-$ $4 \mathrm{~m}$ diatas permukaan laut, Dataran rendah dengan ketinggian $0-30 \mathrm{~m}$ diatas permukaan laut dan Dataran Tinggi dengan ketinggian $30-1200 \mathrm{~m}$ diatas permukaan laut.

Daerah Kab. Langkat dialiri oleh 26 sungai besar dan kecil, melalui kecamatan dan desa-desa, diantara sungai-sungai tersebut adalah : Sungai Wampu, Sungai Batang Serangan, Sungai Lepan, Sungai Besitang dan lain-lain. Secara umum sungai-sungai tersebut dimanfaatkan untuk pengairan, perhubungan dan lain-lain. Langkat juga dikenal dengan daerah Bahorok dimana terjadi fenomena alam angin Bahorok. Angin Bahorok sendiri adalah sebutan lazim untuk angin fohn atau angin lokal atau angin terjun, yaitu angin yang terjadi apabila ada gerakan massa udara yang menaiki suatu pegunungan dengan ketinggian lebih dari 200 meter.

Melihat dari kondisi alam Kabupaten Langkat seperti yang telah diuraikan sebelumnya, tim peneliti melihat adanya potensi untuk pengembangan energi alternatif. Energi alternatif adalah istilah yang merujuk kepada semua energi yang dapat digunakan yang bertujuan untuk 
menggantikan bahan bakar konvensional tanpa akibat yang tidak diharapkan dari hal tersebut. Umumnya, istilah ini digunakan untuk mengurangi penggunaan bahan bakar hidrokarbon yang mengakibatkan kerusakan lingkungan akibat emisi karbon dioksida yang tinggi, yang berkontribusi besar terhadap pemanasan global berdasarkan Intergovernmental Panel on Climate Change.

Daerah Langkat memiliki potensi kecepatan angin, sinar matahari dan sungai yang berlimpah. Ini merupakan sumber energi terbarukan yang dapat dimanfaatkan menjadi energi listrik. Penelitian ini bertujuan untuk mengembangkan produk pembangkit tenaga listrik berbasis energi alternatif. Metode yang akan diterapkan adalah melakukan survei, mengadakan wawancara kepada pengguna untuk mengisi kuesioner, dan mendefinisikan harapan pengguna dengan mengintegrasi model Kano. Konsultan TQM di Jepang Noriaki Kano, telah memberikan model yang sangat berguna mengenai kepuasan pelanggan yang berkaitan dengan karakteristik produk .Menggunakan karakteristik istilah yang tepat di kemudian hari, dan kita akan menggambar perbedaan yang tajam antara kebutuhan pelanggan dan karakteristik produk

\section{Bahan dan Metode Penelitian 2.1 Landasan Teori}

Metode Kano dikembangkan oleh profesor Kano pada awal tahun 1970 untuk menentukan kualitas layanan berdasarkan pada kepuasan pelanggan. Dalam metode Kano, persyaratan pelanggan (kualitas produk / layanan) dikategorikan ke dalam tiga kelompok, yaitu elemen dasar, kinerja, dan kualitas yang diinginkan (Hashim et al, 2012). Model Kano memberikan pendekatan efektif yang efektif dengan mengelompokkan atribut produk berdasarkan persepsi pelanggan dan memahami hubungan antara fungsi produk dan kepuasan pelanggan. (Hsu, dkk, 2007). Seyed Masood Seyedi, dkk (2012), mengatakan bahwa model Kano (teori kualitas yang menarik) umumnya digunakan untuk memperoleh pengetahuan tentang kebutuhan pelanggan (teori kualitas yang menarik) (Chen dan Su, 2006; Gerson, 2003). Ada beberapa elemen dasar dari model KANO untuk pengembangan produk dan kepuasan pelanggan, dan model Kano mengklasifikasikan preferensi pelanggan ke dalam lima kategori seperti menarik, satu dimensi, must-be, acuh tak acuh dan sebaliknya. Kategori ini dinyatakan sebagai berikut. (Kano, 2001).

1. Attractive: Karakteristik kualitas tertentu yang akan diperoleh pada kepuasan pelanggan. Namun, tidak adanya atribut kualitas yang sama bukanlah ketidakpuasan.
Tingkat kepuasan pelanggan akan meningkat secara signifikan dengan meningkatkan karakteristik kinerja. Namun, penurunan karakteristik kinerja akan menghasilkan penurunan kepuasan.

2. Must be : Pelanggan tidak akan puas saat memenuhi atribut kualitas saat ini. Namun, jika produk atau layanan tidak memenuhi persyaratan pelanggan, pelanggan akan sangat puas. Tetapi kepuasan pelanggan tidak akan meningkat di atas netral meskipun karakteristik kinerja tinggi.

3. One Dimensional : Tingkat kepuasan pelanggan berbanding lurus dengan atribut kualitas. Semakin tinggi kualitas elemen satu dimensi, maka kepuasan pelanggan akan semakin tinggi dan sebaliknya. Oleh karena itu, pelanggan jelas dan biasanya menuntut persyaratan satu dimensi.

4. Indefferent : Kualitas tertentu yang berdampak pada kepuasan pelanggan adalah apakah ada atribut kualitas atau tidak.

5. Reverse : Ketika tingkat kepuasan pelanggan berbanding terbalik dengan karakteristik kinerja.

6. Questionable : Kapan tingkat kepuasan pelanggan tidak terdefinisi (ada kontradiksi terhadap respons pelanggan). Dalam model Kano, maksud dari kualitas tersebut dikaitkan dengan tujuan yang sebenarnya dicapai dan atribut ini biasanya diharapkan. Fitur kualitas satu dimensi dikaitkan dengan fitur kualitas yang memuaskan pelanggan ketika harapan mereka terpenuhi, dan sebaliknya. Karakteristik kualitas harus dikaitkan dengan atribut yang harus dipenuhi tetapi dapat mengakibatkan ketidaknyamanan jika tidak terpenuhi (Raharjo, dkk, 2009).

Menurut kategori Kano, tim pengembangan produk harus memahami karakteristik teknis respon mereka. Mereka harus memeriksa karakteristik respon teknis dengan meminta mereka untuk pelanggan mereka dalam bentuk survei pelanggan menggunakan kuesioner Kano . Kuesioner Kano terdiri dari dua pertanyaan kali lipat, pertanyaan fungsional dan pertanyaan disfungsional. Pertanyaan Fungsional meminta sikap pelanggan jika respon teknis yang berfungsi dengan baik. Jika tidak, pertanyaan disfungsi nasional adalah pertanyaan yang menanyakan persepsi pelanggan jika respon teknis tidak bekerja atau tidak ada. Kategori respon teknis dapat ditentukan dengan mempertimbangkan kombinasi jawaban pelanggan. Keterangan dari kuesioner Kano dapat dilihat pada Tabel 1.

Tabel 1. Keterangan Kuisioner Kano 


\begin{tabular}{|c|l|l|}
\hline No & $\begin{array}{c}\text { Atribut Fungsional } \\
\text { /Disfungsional }\end{array}$ & \multicolumn{1}{|c|}{ Skor } \\
\hline $\mathbf{1}$ & & 1. Suka \\
& Kesesuaian dengan & 2. Mengharapkan \\
& fasilitas & 3. Netral \\
& & 4. Toleransi \\
& & 5. Tidak suka \\
\hline $\mathbf{2}$ & & 1. Suka \\
& Ketidaksesuaian biaya & 2. Mengharapkan \\
& dengan fasilitas & 3. Netral \\
& & 4. Toleransi \\
& & 5. Tidak suka \\
\hline
\end{tabular}

Cara perhitungan model Kano dapat digunakan tabel evaluasi kano seperti Tabel 2.

Tabel 2. Evaluasi Kano

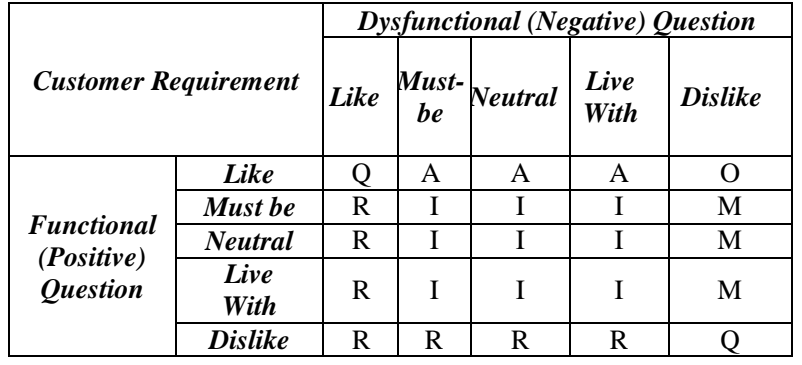

Keterangan :

$\mathrm{Q}=$ Questionable (Diragukan)
$\mathrm{R}=$ Reverse (Kemunduran)
$\mathrm{A}=$ Attractive Menarik)
$\mathrm{I}=$ Indefferent (Netral)
$\mathrm{O}=$ One dimensional (Satu Ukuran)
$\mathrm{M}=\quad$ Must be (Keharusan) kontribusi respon teknis pada kepuasan pelanggan dengan menggunakan rumusberikut:

$$
\begin{gathered}
C S_{i}=\frac{f_{A}+f_{o}}{f_{A}+f_{o}+f_{M}+f_{I}} \\
D S_{i}=-\frac{f_{o}+f_{M}}{f_{A}+f_{o}+f_{M}+f_{I}}
\end{gathered}
$$

Pemilihan respon teknis harus mempertimbangkan beberapa faktor selain koefisien di atas, seperti biaya, waktu, dan tujuan perusahaan. Pemilihan respon teknis melibatkan model matematika untuk mengoptimalkan hasil yang diharapkan. Respon teknis yang dipilih akan menjadi persyaratan desain produk.

\subsection{Metode Penelitian}

Data-data diperoleh dari wawancara dengan tim pakar dan masyarakat pengguna genset di daerah Kabupaten Langkat. Data-data primer dikumpulkan dengan cara pengamatan atau pengukuran langsung, antara lain data kuesioner pendahuluan, data kuesioner terbuka, data kuesioner kepentingan dan kepuasan, data kuesioner karakteristik teknis. data kuesioner hubungan antar karakteristik teknis dan data kuesioner KANO. Data sekunder diperoleh berdasarkan data yang diperoleh dari hasil wawancara dengan supplier produk.
Pada penelitian ini metode pengumpulan data adalah sebagai berikut:

1. Teknik observasi

2. Teknik Survey

3. Teknik dokumentasi,

4. Studi literatur

Variabel-variabel yang akan dipertanyakan kepada konsumen dibuat berdasarkan hasil kuesioner pendahuluan yang menanyakan tentang keinginan masyarakat terhadap pemanfaatan energi alternatif. Variabel disesuaikan dengan hasil rekapitulasi keinginan tersebut dan literatur.

Tahapan pengolahan data diawali dengan mengumpulkan data dari penyebaran kuesioner terbuka sehingga diperoleh modus yang akan digunakan untuk kuesioner tertutup dan Kuesioner KANO. Hasil kuesioner tertutup dan KANO kemudian dituangkan kedalam Model Kano.

Kuesioner Kano dibuat berdasarkan tabel fungsional dan disfungional.

Tabel 3. Atribut Kuesioner

\begin{tabular}{|l|l|}
\hline No & \multicolumn{1}{|c|}{ Atribut } \\
\hline 1 & Harga Pembangkit \\
\hline 2 & Biaya Operasional dan Perawatan \\
\hline 3 & Faktor Keamanan \\
\hline 4 & Kemudahan Pengoperasian dan Perawatan \\
\hline 5 & Daya Tahan Pembangkit \\
\hline 6 & Dampak Lingkungan \\
\hline 7 & Output Energi \\
\hline 8 & Estetika \\
\hline
\end{tabular}

\section{Hasil dan Pembahasan}

Hasil perhitungan dan analisa pengklasifikasian kategori Kano yang diperoleh dapat digunakan untuk pemetaan kategori Kano tiap atribut keinginan konsumen (CR) terhadap semua responden yang dapat dilihat pada Tabel 4.

Tabel 4. Pemetaan Kategori Kano Tiap Atribut

\begin{tabular}{|c|l|c|c|c|c|c|c|}
\hline \multirow{2}{*}{ No } & \multicolumn{1}{|c|}{ Atribut } & \multicolumn{6}{|c|}{ Kategori Kano } \\
\cline { 3 - 8 } & & A & O & M & I & R & Q \\
\hline 1 & $\begin{array}{l}\text { Harga } \\
\text { Pembangkit }\end{array}$ & $\mathbf{5}$ & 4 & 4 & 4 & 0 & 0 \\
\hline 2 & $\begin{array}{l}\text { Biaya } \\
\text { Operasional }\end{array}$ & 0 & 3 & $\mathbf{8}$ & 6 & 0 & 0 \\
\hline 3 & $\begin{array}{l}\text { Faktor } \\
\text { Keamanan }\end{array}$ & 5 & $\mathbf{6}$ & 2 & 4 & 0 & 0 \\
\hline 4 & $\begin{array}{l}\text { Kemudahan } \\
\text { Pengoperasian }\end{array}$ & 2 & $\mathbf{6}$ & 5 & 4 & 0 & 0 \\
\hline 5 & Daya Tahan & 0 & 5 & $\mathbf{8}$ & 4 & 0 & 0 \\
\hline 6 & $\begin{array}{l}\text { Dampak } \\
\text { Lingkungan }\end{array}$ & 0 & 4 & $\mathbf{9}$ & 4 & 0 & 0 \\
\hline 7 & Output Energi & 1 & 4 & $\mathbf{8}$ & 4 & 0 & 0 \\
\hline 8 & Estetika & 1 & 2 & 5 & $\mathbf{9}$ & 0 & 0 \\
\hline
\end{tabular}

Hal yang dilakukan setelah memperoleh jumlah/nilai kategori Kano tiap-tiap atribut terhadap semua responden maka dilakukan penentuan kategori Kano dengan menggunakan 
rumus Blauth's formula. Rekapitulasi Kategori Kano dapat dilihat pada Tabel 5.

Tabel 5. Pemetaan Kategori Kano Tiap Atribut Menurut Blauth's formula

\begin{tabular}{|c|l|c|}
\hline No & \multicolumn{1}{|c|}{ Atribut } & $\begin{array}{c}\text { Kategori } \\
\text { Kano }\end{array}$ \\
\hline 1 & Harga Pembangkit & $\mathrm{A}$ \\
\hline 2 & Biaya Operasional & $\mathrm{M}$ \\
\hline 3 & Faktor Keamanan & $\mathrm{O}$ \\
\hline 4 & Kemudahan Pengoperasian & $\mathrm{O}$ \\
\hline 5 & Daya Tahan & $\mathrm{M}$ \\
\hline 6 & Dampak Lingkungan & $\mathrm{M}$ \\
\hline 7 & Output Energi & $\mathrm{M}$ \\
\hline 8 & Estetika & $\mathrm{I}$ \\
\hline
\end{tabular}

Dari hasil rekapitulasi Kano diketahui bahwa terdapat satu atribut yang berada di kategori Indifferent yaitu Estetika sehingga untuk perhitungan selanjutnya, atribut ini dapat tidak disertakan. Tingkat kepentingan variabel kebutuhan konsumen secara lengkap dapat dilihat pada Tabel 6.

Tabel 6. Customer Importance(CI) terhadap Kategori Kano

\begin{tabular}{|l|r|r|r|r|r|r|}
\hline \multirow{2}{*}{\begin{tabular}{l}
\multirow{2}{*}{$\begin{array}{l}\text { Kebutuhan } \\
\text { Konsumen }\end{array}$} \\
\cline { 2 - 6 }
\end{tabular}} & \multicolumn{5}{|c|}{ Skasil Kuesioner } & \multirow{2}{*}{ CI } \\
\cline { 2 - 7 } & $\mathbf{1}$ & $\mathbf{2}$ & $\mathbf{3}$ & $\mathbf{4}$ & $\mathbf{5}$ & \\
\hline $\begin{array}{l}\text { Harga } \\
\text { Pembangkit }\end{array}$ & 0 & 0 & 1 & 3 & $\mathbf{1 3}$ & 5 \\
\hline $\begin{array}{l}\text { Biaya } \\
\text { Operasional }\end{array}$ & 0 & 0 & 2 & $\mathbf{1 0}$ & 5 & 4 \\
\hline $\begin{array}{l}\text { Faktor } \\
\text { Keamanan }\end{array}$ & 0 & 0 & 5 & 4 & $\mathbf{8}$ & 5 \\
\hline $\begin{array}{l}\text { Kemudahan } \\
\text { Pengoperasian }\end{array}$ & 0 & 0 & 3 & 5 & $\mathbf{9}$ & 5 \\
\hline Daya Tahan & 0 & 1 & 2 & 5 & $\mathbf{9}$ & 5 \\
\hline $\begin{array}{l}\text { Dampak } \\
\text { Lingkungan }\end{array}$ & 0 & 0 & 3 & 4 & $\mathbf{1 0}$ & 5 \\
\hline Output Energi & 0 & 1 & 0 & $\mathbf{1 1}$ & 5 & 4 \\
\hline
\end{tabular}

\section{Kesimpulan dan Saran}

Atribut produk pembangkit tenaga listrik berdasarkan hasil penyebaran kuesioner KANO diperoleh bahwaatribut Harga pembangkit masuk dalam kategori Attractive. Sementara atribut Faktor keamanan dan kemudahan Pengoperasian masuk dalam kategori One Dimensional. Sementara Estetika menjadi satu-satunya atribut yang masuk dalam kategori Indifferent. Melalui penggunaan model Kano, peneliti dapat mengeliminasi atribut untuk tahapan pengembangan produk selanjutnya.

\section{DAFTAR PUSTAKA}

Adia Cahya Purnama, Ridho Hantoro, Gunawan Nugroho, 2013. Rancang Bangun Turbin Air Sungai Poros Vertikal Tipe Savonius Dengan Menggunakan Pemandu Arah
Aliran. JURNAL TEKNIK POMITS Vol. 1, No. 1, (2013) 1-6

Adila Md Hashim \& Siti Zawiah Md Dawal (2012). Kano Model and QFD Integration Approach for Ergonomic Design Improvement. The 2012 Internationl (Summer) Comference on Bussiness Innovation and Technology Management. $57,22-32.1$

Chen YH and Su CT (2006). A Kano-CKM model for customer knowledge discovery. Total Qual Manage 17: 589-608.

Chien-Jung Lai , Chih-Hung Hsu , Hui-Ming Kuo, (2012). An Empirical Study of Constructing a Dynamic Mining and Forecasting System for the Life Cycle Assessment- based Green Supply Chain. Wseas Transactions On Systems, ISSN: 2224-2678.

Chih Hung Hsu, Tsan - Ming Chang, Shih Yuang Wang, Pei Yi Lin. (2007). Integrating Kano's Model into Quality Function Deployment to Facilitate Decision Analysis for Service Quality. Conference on Mathematics and Computers in Bussiness and Economics, Vancouver, Canada, $19-21$.

Cohen, L 1995 Quality Function Deployment : How to Make QFd Work for You (USA : Addison-Wesley Publishing Company) pp 123

Day, Ronald. G 1993 Quality Function Deployment, Linking a Company with Its Costumers (Milwaukee : ASQC Quality Press)

Djoko Adi Widodo, Suryono, Tatyantoro A., Tugino. 2009. Pemberdayaan Energi Matahari Sebagai Energi Listrik Lampu Pengatur Lalu Lintas (Universitas Negeri Semarang)

Gerson T (2003). Development of Customer Needs in the QFD Using a Modified Kano Model. J. Acad. Bus. 27(5):482-500.

Hendry Raharjo, Aarnout C. Brombacher, T. N. Goh, Bo Bergman (2009). On integrating Kano's model dynamics into QFD for multiple product design. Quality and Reliability Engineering International. 351-363.

Hsu-Fang Hung, Hsing-Pei Kao, \& Ying-Shen Juang. (2008), An Integrated Information System For Product Design Planning. Journal Expert Systems with Applications: An International Journal, 35. 338 - 349.

Kao, H.-P., Su, E., \& Wang, B. (2002). IQFD: A Blackboard-Based Multi-Agent System For Supporting Concurrent Engineering Projects. International Journal of Production Research, 40(5), 1235 - 1262.

Kompas GSA. 2012. Pengembangan Energi Angin Memungkinkan. Download 18 April 2012. http://www.energi.lipi.go.id 
Mendoza, N., Horacio A. \& Arturo Molina. (2003), Case Studies in the Integration of $Q F D$, $V E$ and DFMA during the Product Design Stage. The Proceedings of the 9th International Conference of Concurrent Enterprising, Espoo, Finland, 16-18 June 2003

Naseri, K (2014). Algorithm for Cost-optimized QFD Decision-Making Problem, Evolutionary Intelligence, Volume 9, Issue 1-2, pp 21-36.

Pei Kao., Su, E., \& Wang, B. (2010). A Blackboard-Based Multiagent System for Supporting Concurrent Engineering Projects. International Journal of Production Research (Impact Factor: 1.46), $1235-1262$.
Satwiko Sidopekso, dan Anita Eka Febtiwiyanti, 2010. Studi Peningkatan Output Modul Surya Dengan Menggunakan Reflektor. Berkala Fisika ISSN : 1410 - 9662 Vol. 12, No. 3, Juli 2010, hal $101-104$

Seyed Masood Seyedi, Mohammad Shirazifar , Mohammad Reza Dalvand and Mohammad Hadi Zohdi (2012). Optimal Examination And Prioritization Of The Factors Affecting Customers' Satisfaction Using Integrated Quality Function Deployment (QFD) and Kano's model: Case study of Shiraz's Refah bank. African Journal of Business Management Vol.6 (35), pp. 9762-9772. 